\title{
RELAÇÕES ENTRE AS TSM's GLOBAIS E OS VOLUMES DOS PRINCIPAIS RESERVATÓRIOS DE ÁGUA DA PARAÍBA
}

\author{
Manoel F. Gomes Filho ${ }^{1}$, José Oribe Aragão² e Vajapeyam S. Srinivasan ${ }^{3}$
}

\begin{abstract}
RESUMO
Apresenta-se a análise estatística baseada em correlações entre as temperaturas da superfície dos oceanos (TSM's) globais e os volumes dos principais reservatórios (açudes) da Paraíba. Os campos globais dos coeficientes de correlação obtidos referem-se às correlações entre temperaturas médias para o trimestre novembro a janeiro e os volumes dos açudes para cada um dos meses individuais de janeiro a junho, a época chuvosa na região dos reservatórios; os resultados mostram que existem fortes correlações negativas entre as tsm's das regiões do Pacífico, denominadas NINO1+2 e NINO3, e os volumes mencionados. Outra característica apresentada é um cinturão de correlações positivas em ambos os hemisférios, sobre a latitude de $30^{\circ}$ norte e sul.
\end{abstract}

Palavras-chave: temperatura da superfície do mar (TSM) recursos hídricos, açudes, precipitação

\section{RELATIONSHIP BETWEEN GLOBAL SST AND VOLUMES OF THE MAIN WATER RESERVOIRS OF PARAIBA}

\begin{abstract}
This paper presents a statistical analysis based on the correlation between the Global Sea Surface Temperatures (SST) and the volumes of water held in the principal reservoirs of the Paraíba State. The global correlation coefficients were obtained (and refer to the correlation) between the mean SST for the trimester November to January and the volumes of the water in the reservoirs for each of the individual months from January to June, the rainy season in the region of the reservoirs. The results show the existence of a strong negative correlation between the SST's of the Nino1+2 and Nino3 regions of the Pacific Ocean and the volumes of the reservoirs under study. Another feature presented is a positive correlation belt at the latitudes $30^{\circ}$ for both hemispheres.
\end{abstract}

Key words: precipitation, water reservoir, global SST, correlation, water resources

\section{INTRODUÇÃO}

O Estado da Paraíba sofre, entre outros, sérios problemas de estiagem que ocorrem na região Nordeste do Brasil - NEB, fenômeno que, à luz do conhecimento científico atual, está intimamente ligado à circulação atmosférica de larga escala (Walker, 1928; Bjerknes, 1969) causando sérios transtornos às populações nordestinas, principalmente àquelas que vivem nos sertões dos Estados incluídos no Polígono das Secas.

Um dos aspectos que influenciam as chuvas no Nordeste é o fenômeno conhecido por El-Nino; trata-se do aquecimento anormal das águas superficiais do Oceano Pacífico, ao longo da região equatorial (Hastenrath \& Heller 1977; Ali Harzallah et al. 1996; Ropelewski \& Halpert 1987) e cuja conseqüência

\footnotetext{
${ }^{1}$ MSc Meteorologia, Professor Adjunto, DCA/CCT/UFPB, CEP 58.109-970 Campina Grande, PB, mano@dca.ufpb.br

${ }^{2}$ PhD Meteorologia, Pesquisador SECTMA/DEMRH CEP 52061-070 Recife, PE, oribe@ sectma.pe.gov.br

${ }^{3}$ PhD Rec. Hídr., Professor Titular DEC/CCT/ UFPB, srinivas@ rechid.ufpb.br
} 
ocasiona a formação de uma circulação térmica direta envolvendo movimentos ascendentes e descendentes sobre as regiões equatoriais dos Oceanos Pacífico e Atlântico, respectivamente, com movimentos horizontais no sentido leste - oeste. Esta circulação é chamada "Circulação de Walker " e o ramo descendente anômalo desta circulação sobre a região do Atlântico diminui os movimentos ascendentes sobre a Amazônia e o Nordeste do Brasil, causando diminuição na formação de nuvens e reduzindo substancialmente a precipitação sobre essas duas regiões (Caviedes 1973 ); tal fenômeno é caracterizado por episódios que podem ser classificados como fracos, moderados e fortes, dependendo do grau de aquecimento das águas do mar, da sua extensão horizontal e do tempo da duração desse aquecimento. O fenômeno El-Niño ocorre, em geral, associado à fase negativa da Oscilação do Sul, que é uma oscilação na pressão atmosférica a nível médio do mar, em duas regiões distintas do Oceano Pacífico (Tahiti e Darwin) e se denomina ENOS - El-Niño Oscilação do Sul, e tem sido associado, durante muitos anos, às secas no NEB (Caviedes, 1973; Aragão, 1986). Outro fato importante, também normalmente associado às secas nesta região, é o conhecido Dipolo do Atlântico (Moura \& Shukla 1981) em que o Atlântico Tropical Norte está mais quente que o normal e o Atlântico Sul mais frio, uma circulação térmica anômala reduz os movimentos ascendentes sobre o NEB, inibindo a formação de nuvens e reduzindo, em conseqüência, as chuvas. Se por um lado esses fenômenos atuam como inibidores das chuvas sobre a região, por outro lado existem os que atuam como provocadores de precipitações intensas, como é o caso dos sistemas convectivos de mesoescala. Um tipo bem característico desses sistemas surge no Oceano Atlântico, próximo à costa paraibana (Gomes Filho et al., 1996) que se desloca segundo uma trajetória aproximadamente retilínea na direção leste-oeste e chega a atingir o sertão paraibano, provocando chuvas intensas ao longo do seu caminho. Uma das suas principais características é a maior frequiência de ocorrer no mês de março (Gomes Filho et al., 1997) acredita-se que esse tipo de sistema deve transferir uma quantidade significativa de água a um reservatório que esteja localizado em sua trajetória; entretanto, o interesse maior neste trabalho está ligado à influência dos sistemas atmosféricos de grande escala.

Os principais reservatórios d'água da Paraíba estudados estão localizados em regiões de distintos regimes pluviométricos. Ò reservatório Epitácio Pessoa (Boqueirão) localizado na região do Cariri paraibano, cujo principal contribuinte, o Rio Paraíba, nasce em uma região cujo regime pluviométrico apresenta um máximo em março, espera-se que apresente boas correlações com as tsm's do Atlântico. O reservatório Coremas, porém, está sob um regime de precipitação influenciado pelas tsm's do Pacífico, especialmente as regiões NINO1+2 e NINO3; portanto, espera-se que esteja bem correlacionado com as tsm's daquelas regiões.

Este trabalho tem como objetivo principal oferecer uma visão geral da influência da distribuição global das temperaturas da superfície do mar sobre os volumes de água dos principais reservatórios (açudes) da Paraíba que, por sua vez, estão submetidos a diferentes regimes de precipitação, sobre os quais a influência dessas temperaturas já é conhecida.

\section{MATERIAL E MÉTODO}

Utilizando-se as séries de anomalias de tsm's globais e de valores observados dos volumes de dois dos principais açudes da Paraíba (Boqueirão e Coremas) cujas localizações estão indicadas na Figura 1 determinam-se, em primeiro lugar, as

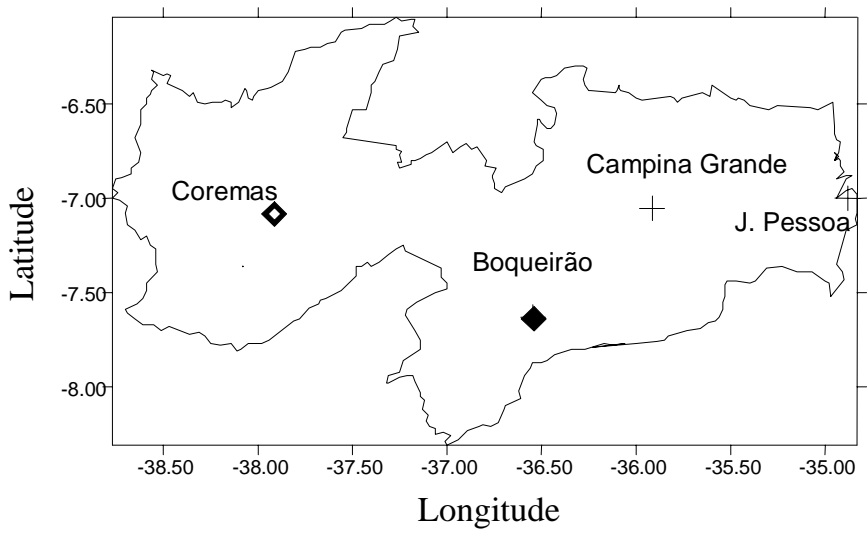

Figura 1. Estado da Paraíba com a localização dos reservatórios considerados no trabalho.

$\diamond$ - Reservatório Coremas

- Reservatório Boqueirão

anomalias no seu volume de água, normalizadas pela média do período utilizado neste estudo, de 1964 a 1993, fazendo-se a subtração dos valores observados mensalmente e do valor médio determinado anteriormente para, em seguida, dividi-lo por aquela média, ou seja:

$$
A_{i}(V)=\left(V_{i}-\bar{V}\right) / \bar{V}
$$

em que :

$A_{i}(V)$ é a anomalia normalizada do volume de qualquer açude no i-ésimo mês

$\mathrm{V}_{\mathrm{i}}$ é o volume médio mensal observado no i-ésimo mês

$\overline{\mathrm{V}}$ é o volume médio para o período considerado no trabalho

Referindo-se às anomalias das temperaturas da superfície do mar em uma base global, tem-se a expressão :

$$
A_{i}(T)=T_{i}-\bar{T}
$$

na qual,

$A_{i}(T)$ é a anomalia de tsm para o i-ésimo mês

$T_{i}$ é a tsm observada no i-ésimo mês

$\widehat{T}$ é a média das tsm's globais para o período considerado (1964 a 93) em 3200 pontos de grade, obtidos do Laboratoire de Metéorologie Dinamique - LMD - de Paris, (Harzallah et al., 1996).

Com as séries dos valores de anomalias dos volumes e das anomalias das tsm's, determina-se a média dessas últimas para dois períodos de três meses, ou seja, um período começando em novembro e terminando em janeiro, e outro se iniciando em fevereiro e findando em abril, para que, deste modo, sejam levados em consideração os efeitos do Pacífico e do Atlântico, respectivamente; a seguir, determina-se o grau das correlações entre essas séries e as anomalias dos volumes para cada um dos meses do ano, para se detectar em que mês os volumes são mais 
influenciados pelas anomalias de tsm, uma vez detectada uma condição desfavorável em termos dessas anomalias, em um desses oceanos. Para se calcular as correlações, as equações gerais da estatística (Marques, 1969) foram utilizadas; por exemplo, a correlação linear foi obtida pela equação:

$$
r=S_{x y} / S_{x} S_{y}
$$

em que :

$$
S_{x y}=\frac{1}{n-1} \sum_{1}^{n}(x-\bar{x})(y-\bar{y})
$$

é a co-variância amostral e os $\mathrm{S}_{\mathrm{x}}$ e $\mathrm{S}_{\mathrm{y}}$ são os desvios-padrão das séries de dados.

Nessas expressões, a variável $\mathbf{X}_{\mathrm{i}}=\left\{\mathrm{x}_{1}, \mathrm{x}_{2}, \mathrm{x}_{3}, \ldots . \mathrm{x}_{\mathrm{N}}\right\}$ corresponde às anomalias de tsm, enquanto a variável $\mathbf{Y}_{\mathrm{i}, \mathrm{j}}$, dada por:

$$
\mathrm{Y}_{\mathrm{i}, \mathrm{j}}=\left\{\begin{array}{l}
\mathrm{y}_{1,1}, \mathrm{y}_{1,2}, \mathrm{y}_{1,3}, \ldots \ldots \ldots \ldots, \mathrm{y}_{1, \mathrm{~K}} \\
\mathrm{y}_{2,1}, \mathrm{y}_{2,2}, \mathrm{y}_{2,3}, \ldots \ldots \ldots \ldots, \mathrm{y}_{2, \mathrm{~K}}
\end{array}\right\}
$$

corresponde às anomalias de volume dos açudes. Usa-se, como índice, uma média para os meses de novembro a janeiro, para as temperaturas da superfície do mar.

Considerando-se o vetor $\mathbf{X}_{\mathrm{i}}$ como o conjunto das médias das tsm's para três meses como, por exemplo, novembro a janeiro, para os anos $\mathbf{i}$, com $\mathbf{i}=1,2, \ldots \ldots$. , n que é correlacionado com a matriz $\mathbf{Y}_{\mathrm{i}, \mathrm{j}}$ das anomalias de volume de determinado reservatório, para o ano i e o mês $\mathbf{j}$ (ver Tabela 1) obtém-se a matriz $\mathbf{R}_{\mathbf{i}, \mathbf{j}}$ formada pelos coeficientes de correlação entre as temperaturas e os volumes.

Na Tabela 1 estão esquematizadas as correlações entre o vetor das anomalias médias de temperatura da superfície do mar e a matriz dos volumes dos reservatórios, representadas pela matriz $\mathbf{R}_{\mathbf{i}, \mathbf{j}}$ de dimensão $\mathbf{N}$ por $\mathbf{K}$, com $\mathbf{N}$ igual ao número de anos e $\mathbf{K}$ igual ao número de meses. Considerando-se que foi usado um campo de tsm global, tem-se uma matriz com essa dimensão para cada ponto da grade; evidentemente, para cada mês é plotado um mapa de correlações para todo o globo, utilizando-se o pacote gráfico GrADS - Grid Analysis and Display (Figuras 2 e 3).

Tabela 1. Correlações entre as anomalias de volume dos reservatórios considerados e as anomalias de tsm para um trimestre (novembro a janeiro ou fevereiro a abril)

\begin{tabular}{cccccc}
\hline Ano & $\mathrm{X}_{\mathrm{i}} \backslash \mathrm{Y}_{\mathrm{i}, \mathrm{j}}$ & $\mathrm{y}_{1}$ & $\mathrm{y}_{2}$ & $\mathrm{y}_{3}$ & $\mathrm{y}_{\mathrm{K}}$ \\
\hline 1964 & $\mathrm{x}_{1}$ & $\mathrm{R}_{1,1}$ & $\mathrm{R}_{1,2}$ & $\mathrm{R}_{1,3}$ & $\mathrm{R}_{1, \mathrm{~K}}$ \\
1965 & $\mathrm{x}_{2}$ & $\mathrm{R}_{2,1}$ & $\mathrm{R}_{2,2}$ & $\mathrm{R}_{2,3}$ & $\mathrm{R}_{2, \mathrm{~K}}$ \\
1966 & $\mathrm{x}_{3}$ & $\mathrm{R}_{3,1}$ & $\mathrm{R}_{3,2}$ & $\mathrm{R}_{3,3}$ & $\mathrm{R}_{3, \mathrm{~K}}$ \\
$\cdot$ & $\cdot$ & & & & \\
$\cdot$ & $\cdot$ & & & & \\
. & $\cdot$ & & & & $\mathrm{R}_{\mathrm{N}, \mathrm{K}}$ \\
1993 & $\cdot$ & & & & \\
\hline
\end{tabular}

Deve-se salientar que no período de análise as demandas e o regime de entrada do fluxo do escoamento foram considerados estáveis. Nos casos em que as condições de demanda e/ou entrada de água nos reservatórios tenham sofrido alterações como, por exemplo, na construção de barragem à montante do açude, instalação de projetos de irrigação, alterações do projeto original da barragem etc utilizou-se, para as correlações, ao invés das anomalias de volume do açude, a entrada total de água no reservatório, obtida através do balanço hídrico, para correlacioná-la com as anomalias de temperatura da superfície do mar, neste caso, a seguinte expressão foi usada :

$$
\left(V_{f}\right)_{n, m}=\left(V_{i}\right)_{n, m}+E_{n, m}-S_{n, m}
$$

em que :

$\left(\mathrm{V}_{\mathrm{f}}\right)_{\mathrm{n}, \mathrm{m}}$ é o volume de água no reservatório no final do mês $\mathrm{m}$ do ano $\mathrm{n}$ (determinado pela curva cota - volume do açude), $\left(\mathrm{V}_{\mathrm{i}}\right)_{\mathrm{n}, \mathrm{m}}$ é o volume de água no reservatório observado no início do mês $\mathrm{m}$ do ano $\mathrm{n}, \mathrm{E}_{\mathrm{n}, \mathrm{m}}$ sendo o volume total de entrada de água no reservatório, ou seja, precipitação efetiva na bacia vezes a área (a variável procurada pelo balanço hídrico) e $S_{n, m}$ é a demanda hídrica total do reservatório que inclui a evaporação, e o abastecimento, no mês $\mathrm{m}$ do ano $\mathrm{n}$ ou, explicitando-se o volume total de entrada de água $\mathrm{E}_{\mathrm{n}, \mathrm{m}}$, obtém-se:

$$
E_{n, m}=\left(V_{f}\right)_{n, m}-\left(V_{i}\right)_{n, m}+S_{n, m}
$$

Uma vez conhecidos o volume final, a demanda hídrica e o volume inicial, pode-se estimar a entrada total de água $\underline{E}$ no reservatório e correlacioná-la com as anomalias das temperaturas da superfície do mar. Esta situação pode ser admitida a partir do ano de 1988 para o reservatório Boqueirão, uma vez que foram construídas muitas barragens à montante do açude no Rio Paraíba.

\section{RESULTADOS E DISCUSSÃO}

Os resultados obtidos para as correlações entre os volumes dos reservatórios d'água na Paraíba e as anomalias de tsm, podem ser agrupados do seguinte modo:

- correlações entre as anomalias de volume do açude Coremas em cada um dos meses do período chuvoso no NEB, de janeiro a junho, e as anomalias médias de tsm para o trimestre novembro a janeiro;

Os mapas globais de correlação, mostrados nas Figura 2 (linhas centrais se cruzam em $0^{\circ}$ de latitude e longitude) apresentam as correlações entre as anomalias de volume do açude Coremas, em janeiro (Fig. 2A) e fevereiro (Fig. 2B), e as anomalias médias de tsm's globais para o trimestre novembro a janeiro. Pode-se notar, nas figuras, regiões do oceano com correlações negativas no Pacífico leste e central, próximo à costa sul-americana. Coincidentemente, essas são as regiões denominadas NINO3 e NINO1+2. Algumas regiões positivamente correlacionadas aparecem no Pacífico, principalmente ao longo do cinturão de altas subtropicais, centrado em $30^{\circ}$ sul e norte. $\mathrm{Na}$ área do Atlântico aparece uma área de correlações negativas ao norte de $30^{\circ}$ sul, estendendose desde a costa da África até o Brasil. Uma pequena região de correlações positivas surge na região da alta semi - estacionária do Atlântico sul, cujos resultados devem ser recebidos com cautela, pois as observações nessas regiões são em número 
menor que nas regiões tropicais, especialmente no hemisfério sul. Para o mês de março (Fig. 2C) as correlações negativas do Pacífico equatorial ficam espalhadas até a área central daquele oceano; as correlações negativas do Atlântico equatorial sul são intensificadas e uma área de correlações positivas surge no Atlântico subtropical norte, centrado em $30^{\circ}$ norte. Uma vez mais, as áreas no cinturão de altas subtropicais estão positivamente correlacionadas. Considerando-se o mês de abril (Fig. 2D) a área com anomalias negativas próximo à costa oeste sul-americana, apesar de menos extensa, apresenta correlações maiores (com valores de até -0,8) que as observadas nos meses de fevereiro e março, e permanecem sobre o cinturão subtropical as correlações positivas já observadas, porém com valores maiores (da ordem 0,7); praticamente, todo o Oceano Atlântico neste mês está correlacionado positivamente, com exceção do extremo norte e de um pequeno núcleo próximo à África, no
Atlântico tropical norte; no mês de maio, continuam ainda fortes correlações negativas nas áreas NINO3 e NINO1+2, a exemplo do mês anterior. $\mathrm{O}$ cinturão com núcleos de correlação positiva ao redor do globo nos oceanos subtropicais insiste, porém menos intenso que nos meses de março e abril. Na área do Atlântico, as correlações são positivas, embora pequenas, à exceção de uma pequena área, ao norte do paralelo de $30^{\circ}$ norte (Fig. 2B).

O mapa das correlações das tsm's globais para março, com as anomalias de volume para Coremas (média para janeiro a março) Figura 2C, apresenta áreas negativamente correlacionadas nas regiões NINO3 e NINO1+2 e praticamente em toda a área do Atlântico tropical sul. Os cinturões subtropicais norte e sul continuam positivamente correlacionados, assim como a área subtropical norte do Atlântico; no mês de abril, as correlações negativas da região que compreende as áreas NINO3 e NINO1+2 estão mais concentradas próximo à costa

A: Janeiro

B: Fevereiro
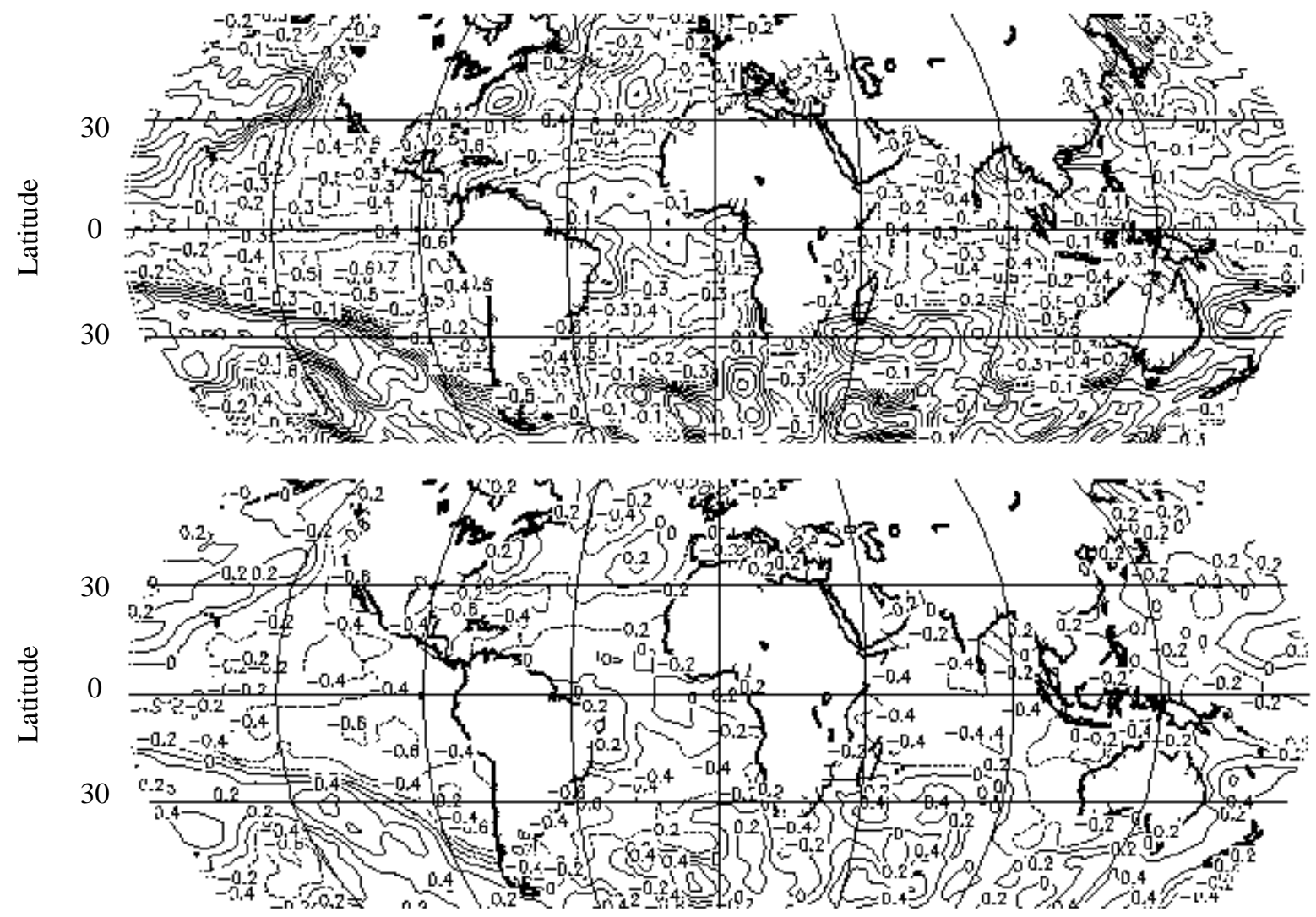

C: Março

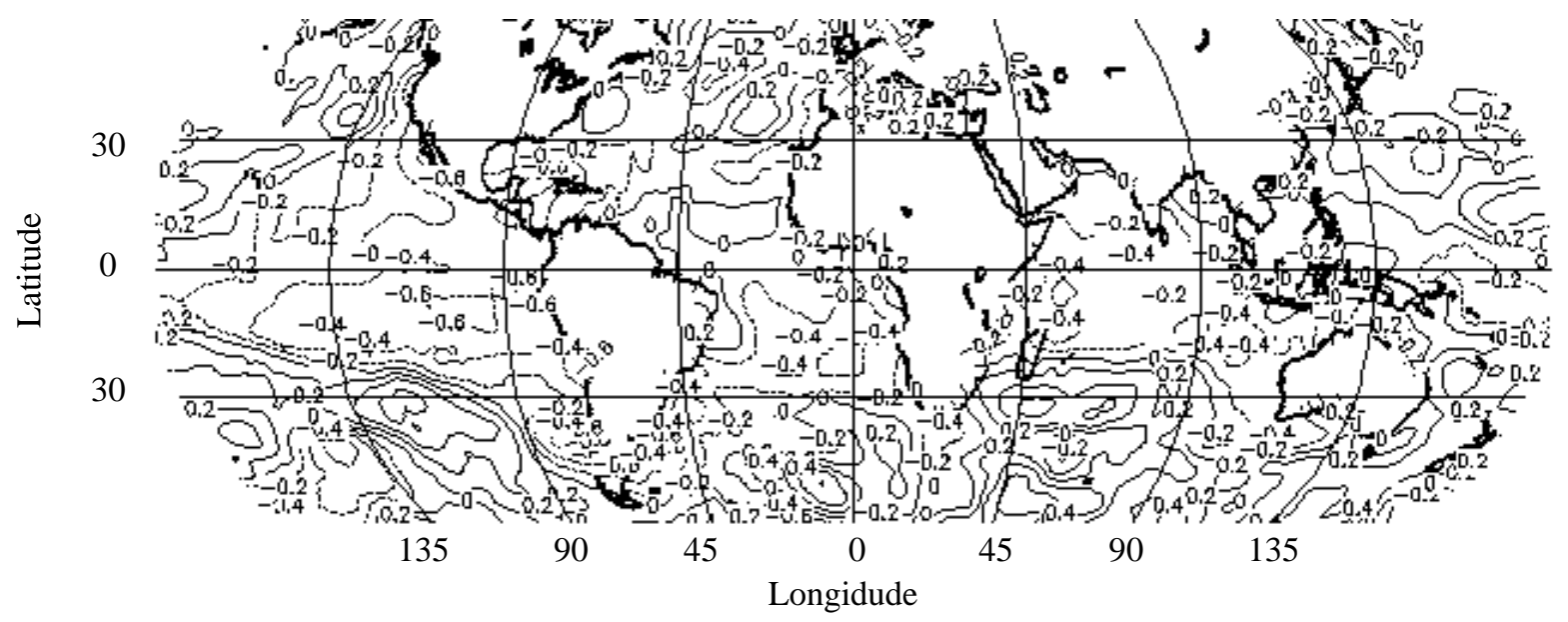

Figura 2. cont. 
D: Abril

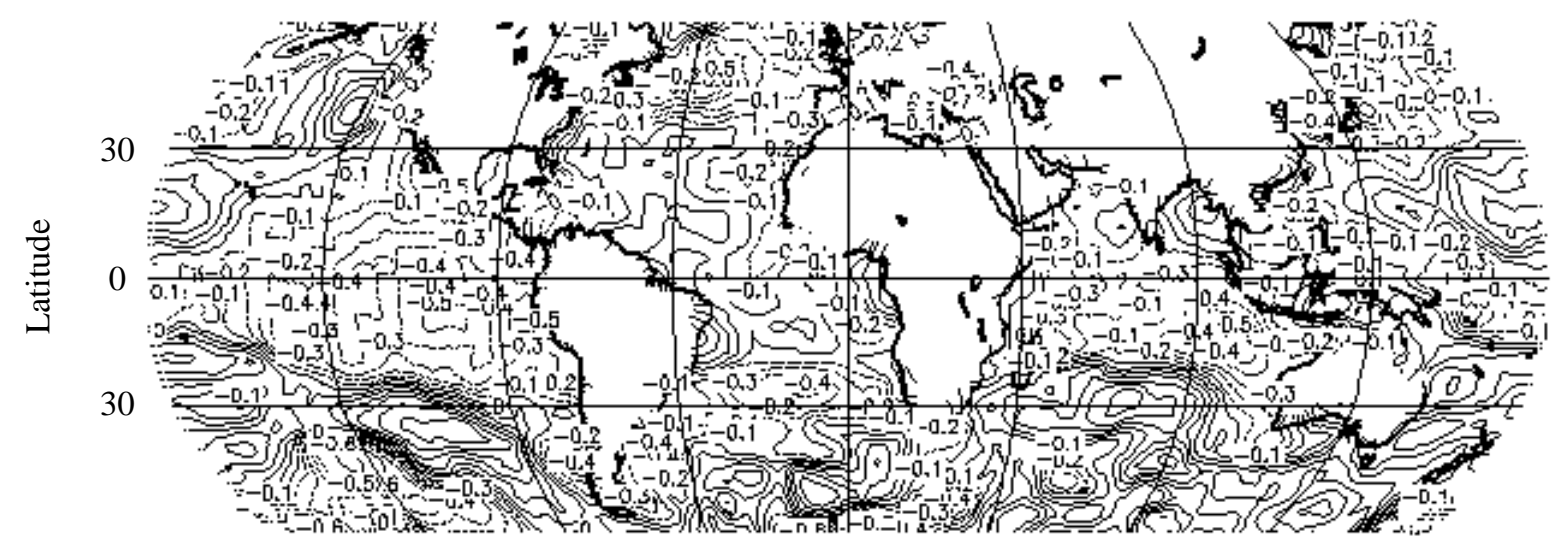

E: Maio

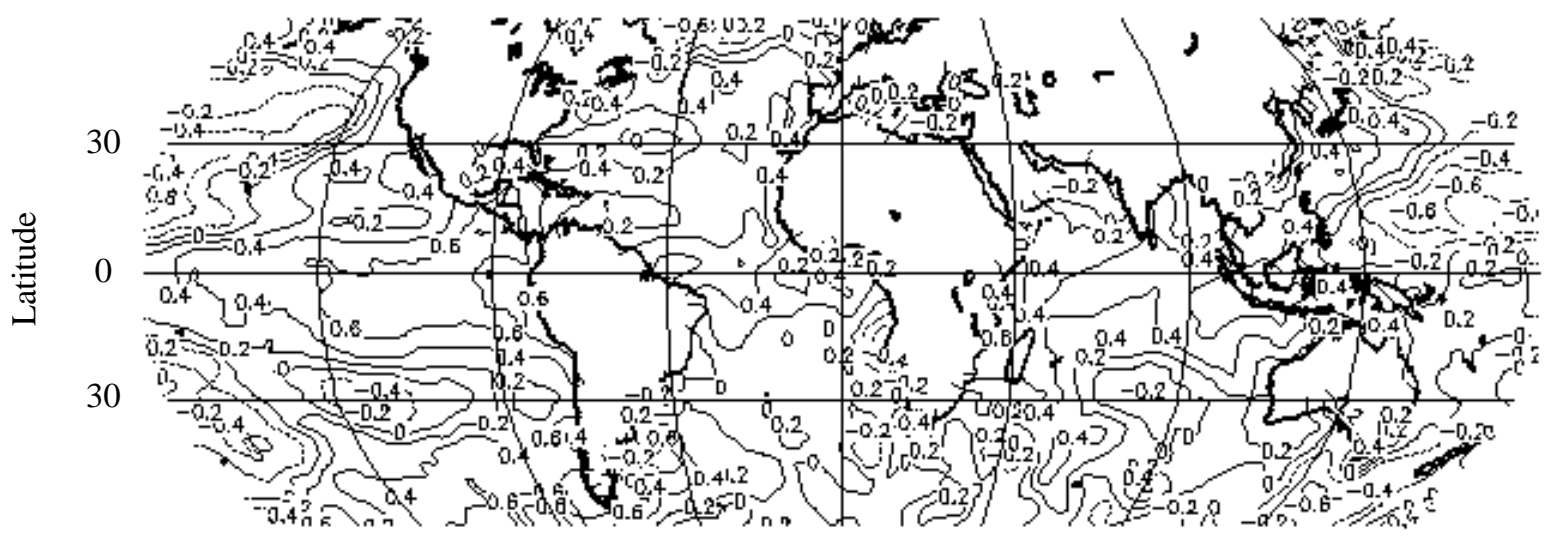

F: Junho

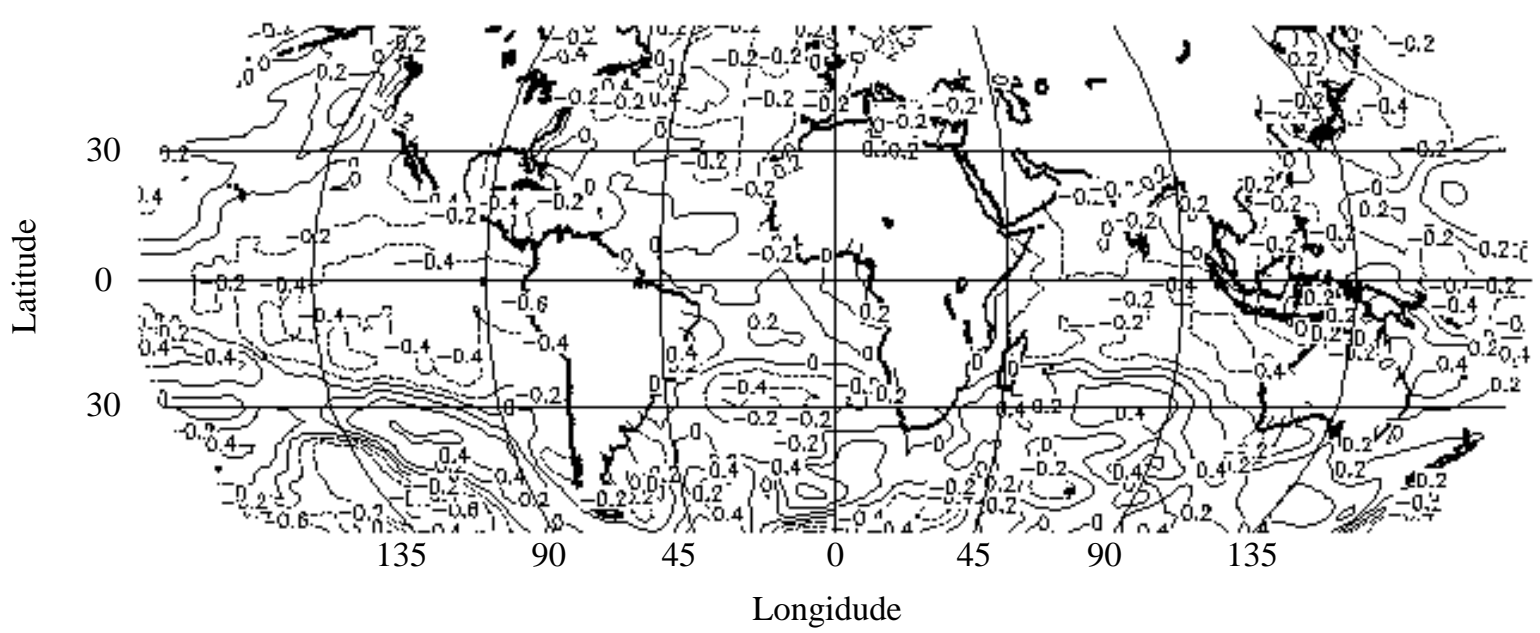

Figura 2. Correlações entre as anomalias dos volumes do reservatório Coremas, para meses de Janeiro a Junho, e as anomalias de tsm, médias para novembro a janeiro

oeste da América do Sul, com valores semelhantes aos apresentados no mês anterior. Surgem áreas negativamente correlacionadas no Atlântico tropical, mais ou menos sobre a área de atuação da Zona de Convergência Intertropical - ZCIT, e uma área positivamente correlacionada no Atlântico subtropical norte, porém com valores baixos. As áreas dos cinturões das altas subtropicais permanecem positivamente correlacionadas e essas áreas de correlações positivas aumentam substancialmente em todo o globo, neste mês (Fig. 2D).

No mês de maio (Fig. 2E) as anomalias negativas com valores em torno de $-0,6$ permanecem próximas à costa oeste da América do sul. No Oceano Pacífico, as áreas positivamente correlacionadas ocupam quase toda a área do oceano, especialmente aquelas do cinturão de altas subtropicais, que se espalham na direção do equador. O Oceano Atlântico está negativamente correlacionado, à exceção de uma pequena área na região subtropical norte. Em junho, como mostra a Figura $2 \mathrm{~F}$, a situação do mês anterior fica mantida, com poucas mudanças como, por exemplo, a região da ZCIT, que se torna mais negativa. $\mathrm{O}$ número de áreas positivamente correlacionadas aumenta substancialmente em volta do globo terrestre.

Considerando-se as correlações para o açude Boqueirão, conforme a Figura 3A, vê-se que no mês de janeiro há inversão no sinal, com relação às correlações apresentadas para o açude Coremas, isto é, as áreas do Pacífico denominadas NINO1+2 e NINO3, estão positivamente correlacionadas com os volumes, assim como todo o Oceano Atlântico tropical, sendo mais 
intensas no setor da alta semi-estacionária do Atlântico norte. $\mathrm{Na}$ área do Atlântico, ao sul dos trópicos, surgem correlações negativas, porém pequenas; em fevereiro (Fig. 3B) as correlações do setor do Pacífico permanecem positivas, porém com menor intensidade e abrangem área maior. No Atlântico, na área de atuação da ZCIT aparecem correlações negativas com baixa intensidade. A área com correlações negativas no setor da alta semi-estacionária do Atlântico sul expandiu-se na direção norte, formando uma grande área, inclusive próximo ao continente, no setor da Zona de Convergência do Atlântico Sul - ZCAS.

A partir da Figura $3 \mathrm{C}$ vê-se que, no mês de março, as correlações, tanto no Pacífico como no Atlântico, se tornam negativas, abrangendo também as áreas NINO1+2 e NINO3. O setor do Atlântico tropical está caracterizado pela presença de correlações negativas de norte a sul, porém existe uma área positiva na costa do Brasil. No mês de abril, Figura 3D, há alternância de correlações positivas e negativas em todos os oceanos, com alguns pequenos núcleos de correlações negativas mais intensas ao longo da área equatorial.

Em maio (Fig.3E) há uma grande área com correlações negativas ao longo do setor NINO1+2 e NINO3, no Atlântico; a alternância de centros positivos e negativos predomina de norte a sul; já em de junho, como mostra a Figura 3F, uma grande área com correlações positivas significativas está situada no Pacífico, estendendo-se desde a costa da América do sul até o Pacífico equatorial central. No Atlântico, o setor da ZCIT, ao norte do equador, está positivo e tem centro negativo no setor da alta subtropical sul. No setor norte existe uma área positiva próxima ao Canadá.

A: Janeiro

B: Fevereiro

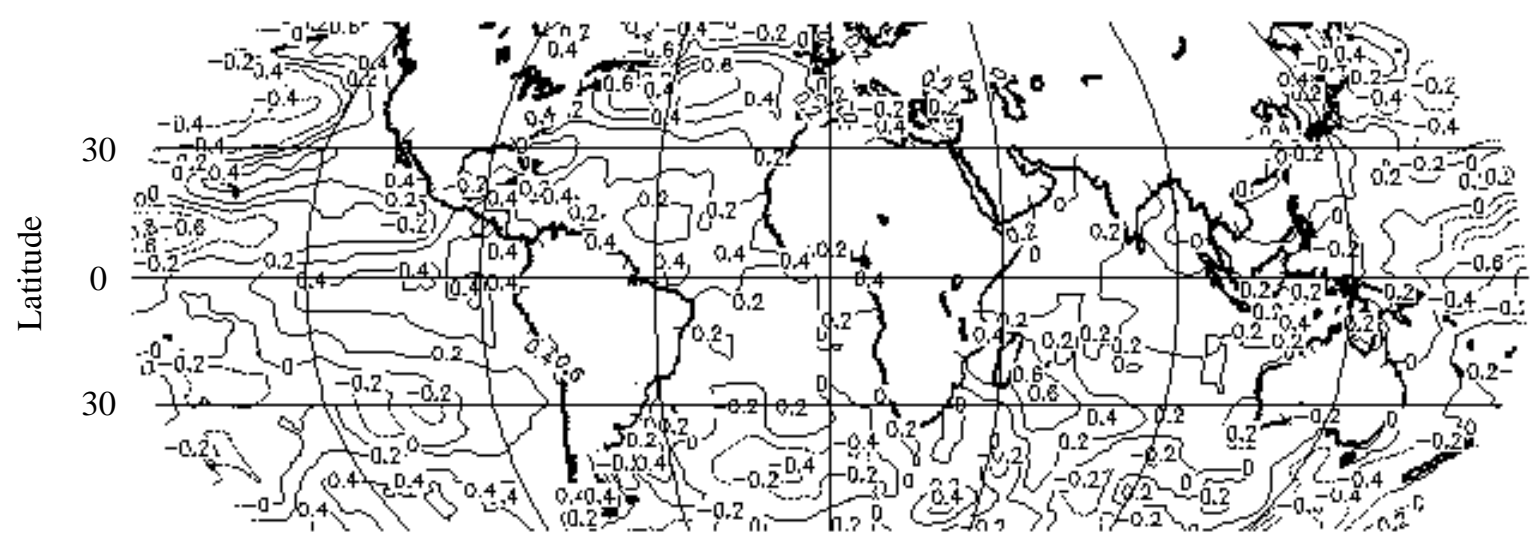

C: Março
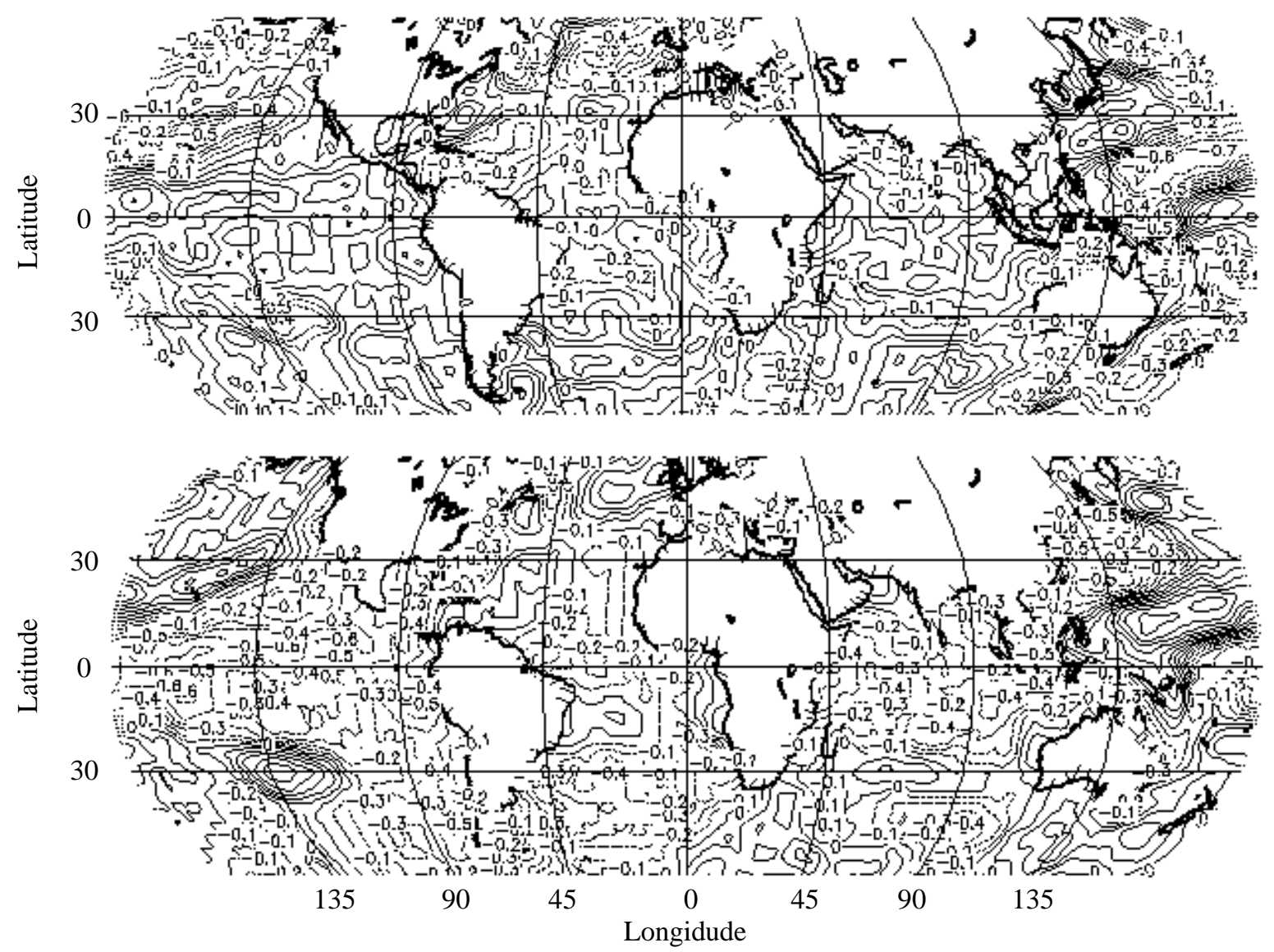

Fig. 3 cont. 
D: Abril

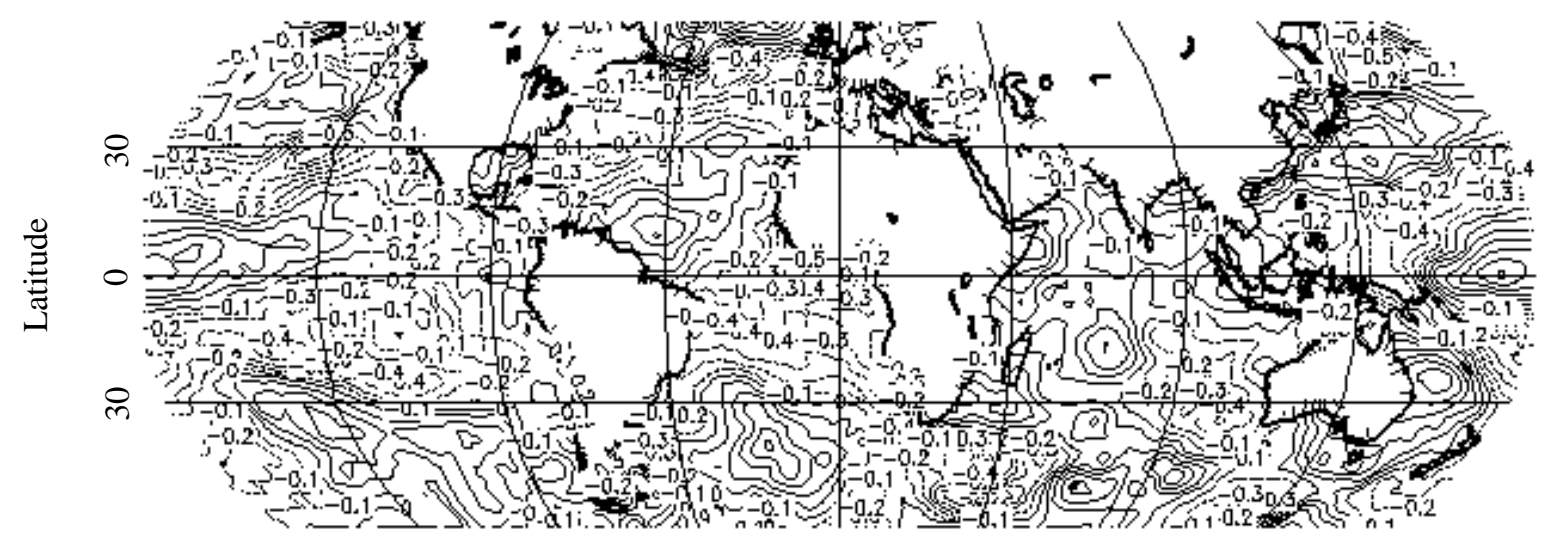

E: Maio

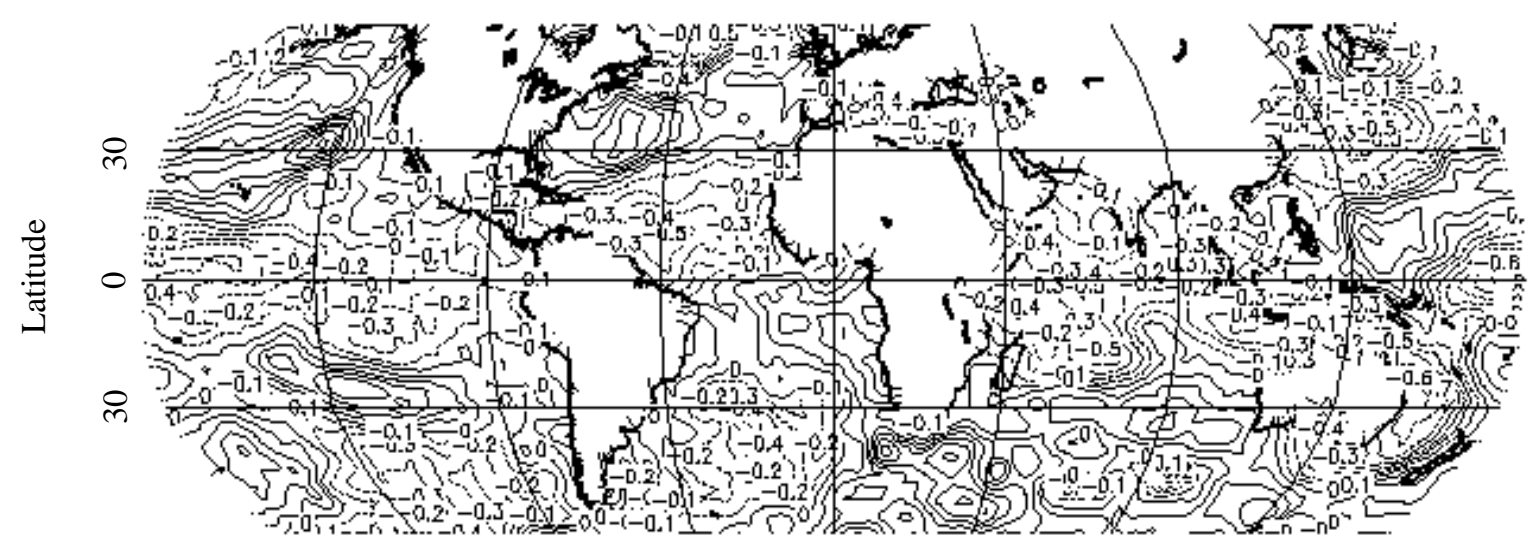

F: Junho

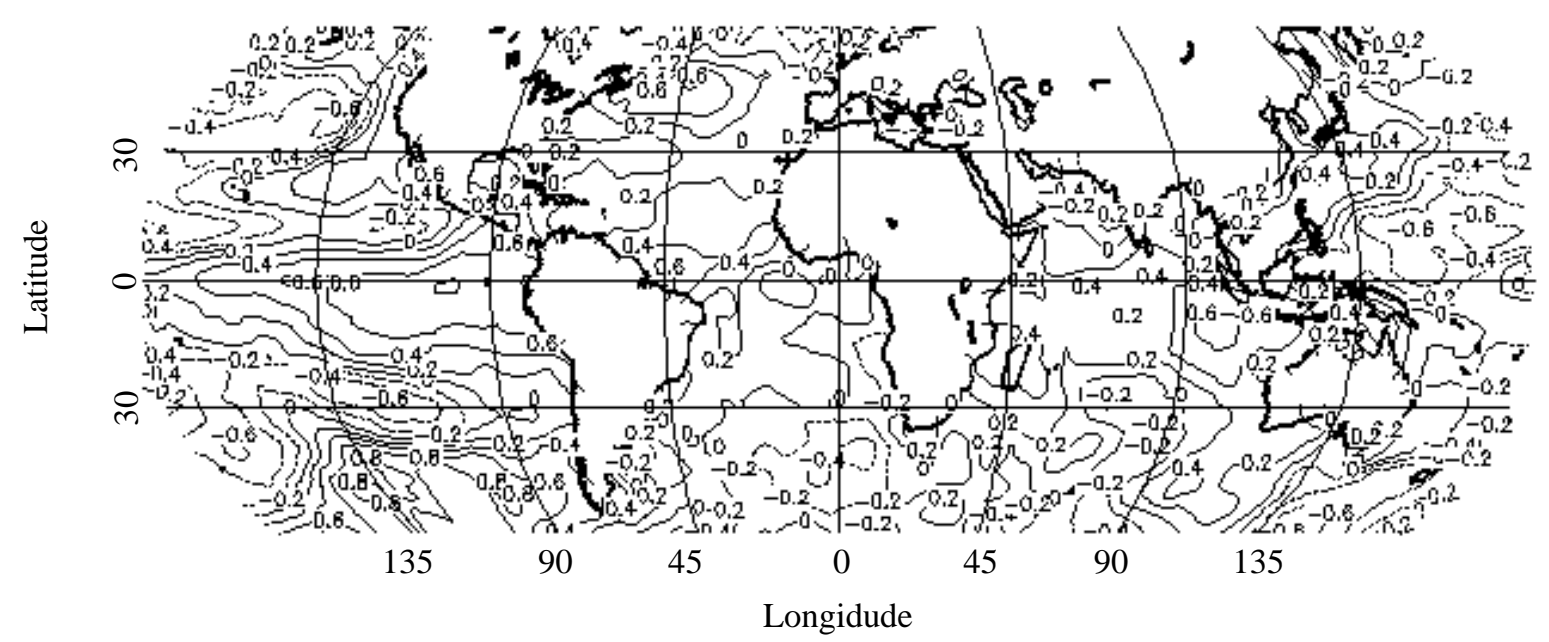

Figura 3. Correlações entre as anomalias dos volumes do reservatório Boqueirão, para meses de Janeiro a Junho, e as anomalias de tsm, média para fevereiro a abril

Como pode ser observado a partir desses resultado, a influência da distribuição de anomalias de temperatura da superfície do mar (TSM) sobre os reservatórios de água na Paraíba considerados neste trabalho, sugere que, para o reservatório Boqueirão, a influência maior é do Oceano Atlântico sul, correlações positivas em sua maioria, indicando que águas quentes nesse oceano afetariam positivamente os volumes daquele reservatório enquanto o Oceano Pacífico, por sua vez, apresentando correlações negativas, influencia negativamente o reservatório Coremas, como era de se esperar, pois nos episódios El-Niño, águas quentes naquele oceano ocasionam redução nas chuvas e, conseqüentemente, diminuição dos volumes observados.

\section{CONCLUSÃO}

Com base nos resultados apresentados, pode-se concluir que a distribuição global das temperaturas da superfície do mar influenciam os volumes dos reservatórios d'água da Paraíba, tanto quanto a precipitação, que tem sido mais estudada em anos recentes. O sinal do El-Niño aparece muito claramente nas áreas denominadas NINO1+2 e NINO3, representado pela distribuição de correlações negativas ao longo do Pacífico Equatorial e, de forma igualmente clara, surge o sinal do Dipolo do Atlântico, quando se observam as correlações, usando-se as anomalias de tsm, média para fevereiro a abril. Alguns outros sinais da influência, como é o caso das correlações positivas ao longo do cinturão das altas pressões subtropicais, precisam de 
um estudo mais detalhado para melhor caracterização; para esses dois principais reservatórios ora estudados, Coremas e Boqueirão, a influência dos sistemas atmosféricos e oceânicos, de grande escala, está caracterizada, o que encoraja pesquisas futuras para se estender essa metodologia a reservatórios localizados em outros Estados do Nordeste.

\section{AGRADECIMENTOS}

Ao mestrando Edglay Enéas de Almeida, pelo apoio no uso do programa Fortran, para cálculo das correlações. À Professora Margritt H. Nietzsche, pelas sugestões e comentários sobre as estatísticas e suas interpretações. Ao Professor T.V. Ramana Rao, pelas sugestões apresentadas: Ao LMD/Paris, pelo fornecimento das séries de tsm do seu acervo e, finalmente, aos revisores anônimos pelas suas sugestões sobre o trabalho.

\section{REFERÊNCIAS BIBLIOGRÁFICAS}

ARAGÃO, J.O.R. A general circulation model investigation of the response to El Niño, Colorado: NCAR / CT - 100, 1986, 144 p. PhD Thesis

BJERKNES, J. Atmospheric teleconnections from the equatorial Pacific. Monthly Weather Review, Boston, v.97, p.163172, 1969

CAVIEDES, C.N. Secas and El Nino: Two simultaneous climatical hazards in South America. Proceedings of the Association American Geography, Washington, v.5, p.4449, 1973
GOMES FILHO, M.F. ; SOUZA, E.P. ; BECKER, C. T. Sistemas convectivos de mesoescala com precipitação intensa na Paraíba : Um estudo de caso. Revista Brasileira de Meteorologia, São Paulo, v.11, p.36-43. 1996

GOMES FILHO, M.F. ; CAVALCANTI, E.P. ; SILVA, A.R. Análise da precipitaçãodo mês de março em Campina Grande, Paraíba, no período 1987 a 1996. Revista Atmosfera \& Água, Maceio, v.II, p.12-15, 1997

HARZALLAH, A.; ARAGÃO, J.O.R. ; SADOURNY, R. Interannual rainfall variability in northeast Brazil: Observation and model simulation. International Journal of Climatology, Boston, v.16, p.861-878, 1996

HASTENRATH, S.; HELLER, L. 1977: Dynamics of climate hazards in Northeast Brazil. Quarterly Journal of the Royal Meteorological Society, London, v.103, p.77-92.

MARQUES, R.M. Elementos de Estatística, Campinas, São Paulo: Instituto Central de Matemática. Departamento de Estatística - UNICAMP, 1969.

MOURA, A.D.; SHUKLA, J.: On the dynamics of drought in Northeast Brazil :observations, theory and numerical experiments with a general circulation model. Journal of the Atmospheric Sciences,. Boston, v.38, p.2653-2675, 1981

ROPELEWSKY, C.F. HALPERT, M.S. Global and regional scale precipitation patterns associated with the El Niño/Southern Oscillation. Monthly Weather Review, Boston, v.115, p.1606-1626, 1987

WALKER, G.T. Ceará (Brazil) famines and the general air movement.Beitrait Physic Freinen Atmosphare, Berlim v.14, p.88-93, 1928 